\title{
STUDY OF ELDERLY SUICIDE IN A RURAL TEACHING HOSPITAL IN SOUTH INDIA
}

P.N. Venkatarathnamma1, Mohan Reddy², A.L. Yashwanth³, Anil Kumar Mannava ${ }^{4}$, Gautham Gundabolu 5

\section{HOW TO CITE THIS ARTICLE:}

P.N. Venkatarathnamma, Mohan Reddy, A.L. Yashwanth, Anil Kumar Mannava, Gautham Gundabolu. "Study of Elderly Suicide in a Rural Teaching Hospital in South India". Journal of Evolution of Medical and Dental Sciences 2014; Vol. 3, Issue 07, February 17; Page: 1664-1671, D0I: 10.14260/jemds/2014/2040

ABSTRACT: OBJECTIVE: To study prevalence, risk factors associated with suicide in the elderly and the outcome to treatment. MATERIALS AND METHOD: This was a prospective study conducted at rural medical college Hospital. 980 cases of suicidal attempt were admitted to intensive care unit and medical wards, starting from 1-1-2010 to 1-1-2012 (25 months). The data was analyzed for age, sex, type of suicide attempted, treatment given and outcome. Patient evaluation, history and poison/drug review were done in detail. On recovery, family interview, patient psychoanalysis and counseling was done. Drugs were given accordingly. RESULTS: Total number of patients with suicidal attempt was 980 in this study, "elderly group with suicide" were 124(7.9\%), Pesticide consumption was the commonest cause, found in in 87 cases (70\%) followed by drugs in 31(25\%). Poverty was common in $70(86.8 \%), 121(97.1 \%)$ were from rural residence, 102(82.25\%) were illiterate and in 88 cases (80\%) significant psychiatric symptoms were found. CONCLUSION: Suicide in older adults is caused by many psychosocial risk factors(loss of social roles, the death of closer ones, declining health, isolation, financial constraints, decreased cognition), which produce feelings of hopelessness and depression. Depression has been reported as the most common but underdiagnosed in older adults, which is often diagnosed only after the suicide attempt. The National Strategy for Suicide Prevention creates a framework for suicide prevention for the nation. It is designed to encourage and empower groups and individuals to work together.

KEYWORDS: Elderly, Suicide, Depression.

INTRODUCTION: WHO defined suicidal act as the injury with varying degrees of lethal intent, and suicide is defined as a suicidal act with fatal outcome. ${ }^{1}$ There is a dramatic growth in the proportion of the population of the elderly age groups which, in India is currently the second largest in the world. Suicide among the elderly is a critical public health problem. There is an increase in suicide rates in developed and developing countries. ${ }^{2}$ Most developed world countries have accepted the chronological age of 65 years as a definition of 'elderly' or older person. In most gerontological literature people above 60 years of age are called as old and as constituting the elderly segment of the population. ${ }^{3}$ As per WHO guideline people aged 60 to 74 are called elderly, late adulthood, or old age, this refers to the stage of the life cycle that begins at age 65. This older segment above 60 years of age constituted about $7.2 \%$ of total in 2003 and beyond 65 years it was $13.2 \%$ in $2010.2,3$ Table- 1 also shows elderly people per 100 population, in 2001-7.5\%, 2011-8.2\% and projected for 2021 it is 9.9\%. In India during 1984-85, ICMR survey showed 8.5\% prevalence of psychiatric illness in elderly. ${ }^{5}$ 


\begin{tabular}{|c|c|}
\hline Year & Elderly /100 population \\
\hline 2001 & $7.5 \%$ \\
\hline 2011 & $8.2 \%$ \\
\hline 2021 (projected) & $9.9 \%$ \\
\hline
\end{tabular}

Table-1: Showing elderly people per 100 populations

\section{OBJECTIVES:}

(1) To study prevalence and various risk factors associated with suicide in the elderly.

(2) Outcome of treatment.

METHODOLOGY: This was a prospective study, conducted by the departments of Medicine and Psychiatry at Sri. R. L. Jalappa Hospital and Research Centre, attached to Sri Devaraj URS Medical College, Kolar. This is a tertiary care hospital situated in a rural area of Karnataka state in South India. Kolar is a small district, bordered by Andhra Pradesh and Tamilnadu states very closely.

A total number of 980 cases of suicidal attempt were admitted to intensive care unit and medical wards, starting from 1-1-2010 to 1-1-2012 (25 months). The data was analyzed for age, sex, mode of suicide attempt, socio economic status, treatment given and outcome. Detailed patient evaluation, personal history, family interview, a review of medications for underlying psychiatric illness and medical co-morbidities was done. All this data was entered into proforma designed for the study and verbal consent was taken for the study.

Baseline complete blood count, serum electrolytes, blood urea, serum creatinine, glucose, liver function test, blood smear, radiography, HIV, urinalysis and Electrocardiogram were done in all cases and Arterial blood gas analysis, Echocardiogram, Electroencephalogram, computed tomography brain imaging, MRI, CSF analysis, VDRL and drug analysis were done in selected cases based on patient requirement. The primary management of the suicide cases was done by the physician. Initial treatment given: stomach wash, Antibiotics, Antacids, Atropine, Oxime, supportive measures like, intravenous fluids, Ryle's' tube feeds and ventilator support. Hemodialysis was done in 7 cases.

Following recovery the Psychiatry unit did stepwise management i.e. examined all patients' mental status, applied MMSE in cooperative cases, interviewed family members, counseled the patient, counseled the family and patients' close friends, instituted anti-depressants, anxiolytics and antipsychotics and psychotherapy was given. ${ }^{7}$

RESULTS: Total number of patients with suicidal attempt was 980 in this study. Out of this suicides in elderly age were $124(7.9 \%), 84$ were males (67\%) and 40 were females (33\%) (Table-2).

\begin{tabular}{|l|c|c|}
\hline \multicolumn{1}{|c|}{ Sex } & $\begin{array}{c}\text { General group with } \\
\text { suicidal attempt (n-856) }\end{array}$ & $\begin{array}{c}\text { Elderly patients (60 years } \\
\text { and above, n-124) }\end{array}$ \\
\hline Male & 468 & $84(67 \%)$ \\
\hline Female & 388 & $40(33 \%)$ \\
\hline Total & 856 & 124 \\
\hline
\end{tabular}




\begin{tabular}{|l|c|c|}
\hline All age group- $856+124=980$ & $1.2: 1$ & $2.1: 1$ \\
\hline Ratio & Table-2: Shows total number of general group attempted \\
suicide and number of elderly with suicide attempt admitted
\end{tabular}

Male to female ratio is 2.1-1. Age of patients in years is 60 and above. This study of total 980 patients shows, elderly "suicide attempters" comprising 124(7.9\%) (Fig-1). The ratio of general population with suicidal attempt to elderly who attempted suicide is 6.90:1

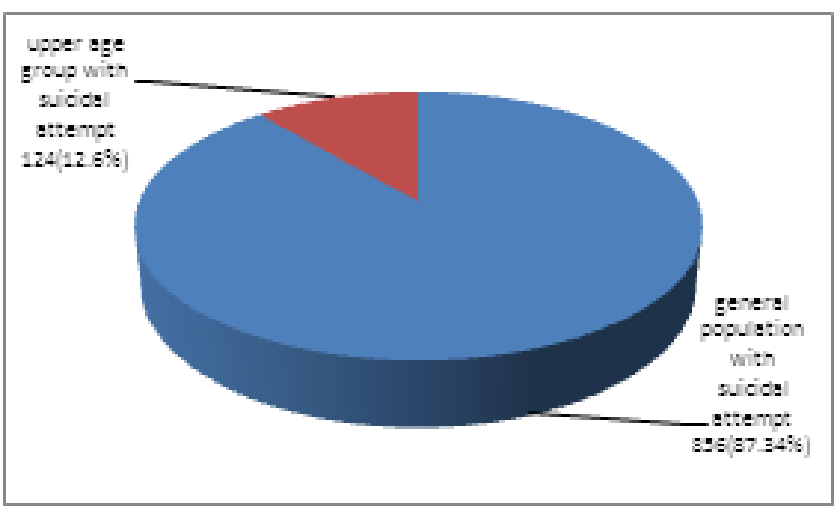

\section{Fig. 1: Shows total cases of general population and elderly age group with suicidal attempt}

Viewing age distribution, majority of cases was observed between 60 - 65 years, 111(90\%) and between 66-85 years, it is $13(10 \%)$ (Fig-2)

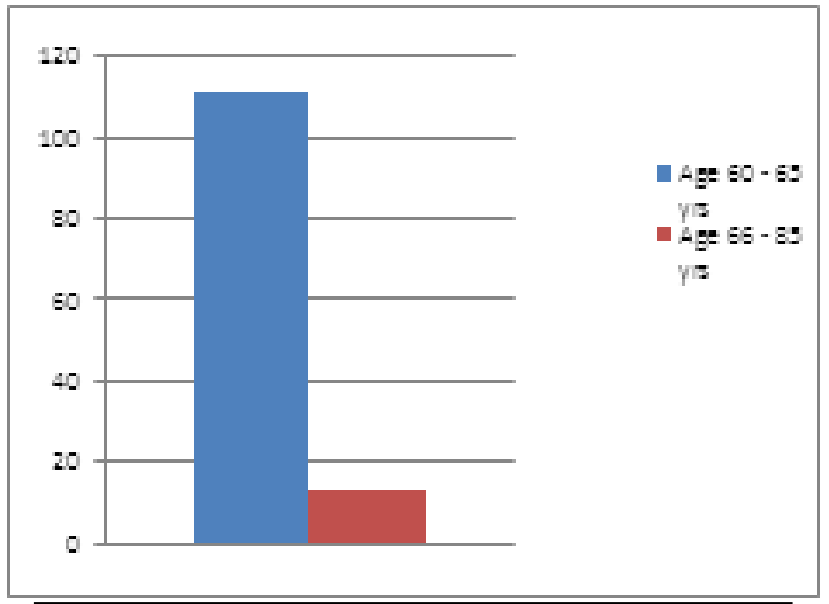

\section{Fig. 2: Shows age distribution in elderly} population with suicidal attempt

All were married, there were 10 widows already and recent demise of spouse was revealed in 3 patients. (Table-3). 


\begin{tabular}{|c|c|c|c|c|}
\hline Gender & Total & Married & Recent demise of spouse & Divorce \\
\hline Male & $84(67 \%)$ & $84(67 \%)$ & $2(2.3 \%)$ & None \\
\hline Female & $40(33 \%)$ & $\begin{array}{c}40(33 \%) \\
\text { (earlier widows-10) }\end{array}$ & $1(2.1 \%)$ & None \\
\hline
\end{tabular}

Table-3: Shows gender distribution and marital status

All belonged to Hindu religion and nobody from any other non-Hindu religion was found. $121(97.1 \% \%)$ patients came from rural areas, i.e. the farming community and $3(2.4 \%)$ from urban residence. 123 cases were indoor attempts and only 1 was an outdoor attempt. All deliberately harmed themselves with high suicide intent. In majority i.e.70 cases (86.8\%) lower socioeconomic status (below poverty line) was found. There was no educational attainment in 102 (82.25\%) cases. Most common method chosen for suicidal purpose was pesticide in 87 cases (70\%), next being, drugs in 31cases(25\%), over the counter preparations like Paracetamol, Chlorpheniramine, Ranitidine and Alprazolam, Levothyroxine, antihypertensives, Antipsychotics, Oral hypoglycemic agents and unknown poly drug consumption, 6 cases(4.8\%) combined pesticide with alcohol, partial hanging was found in 3 cases(2.4\%), datura seeds in 1 case $(0.8 \%)$, nitrobenzene in 1 case $(0.8 \%)$ and rat poison consumption in 1 case(0.8\%). Fig-3.

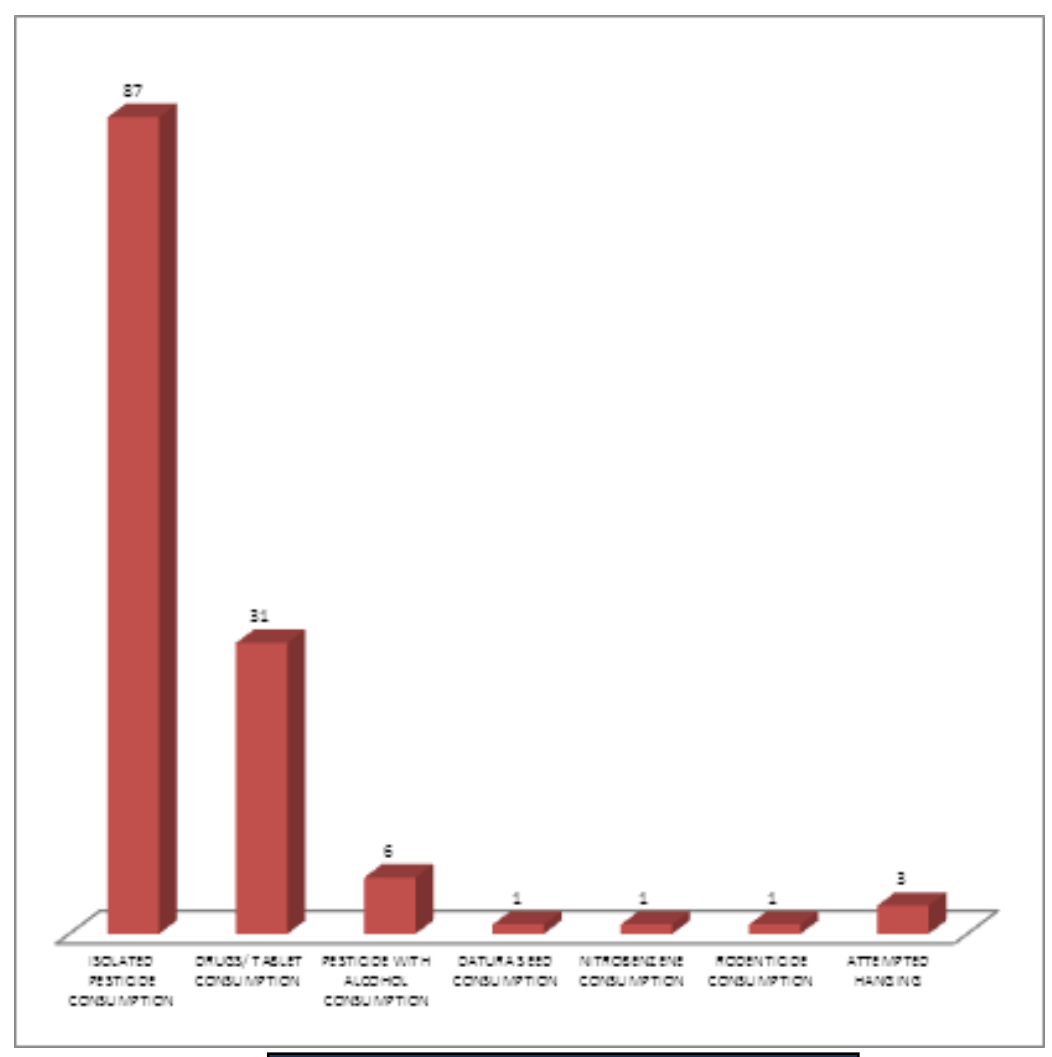

Fig. 3: Shows modes of suicide 
The underlying single or multiple medical co-morbidities were found in $18(14.5 \%)$ cases, ethanol abuse(6), diabetes (3), hypertension (4), ischemic heart disease (4), bronchial asthma (1), myxedema (1), HIV(1) and severe anemia (1)

CT scan brain- was abnormal in 6 patients (hypertensive leucoencephalopathy and lacunar infarcts).

Psychological risk factors were elicited in the 110 survivors of failed suicide; these were associated with suicide behavior. Significant psychiatric symptoms elicited in 88 cases (80\%) were, recent onset of insomnia/ hypersomnia, withdrawn, reduced appetite, self-blaming, headache, body aches, negativity, disinterest in routine work, unprovoked aggressiveness, moody, restless state, episodic tearfulness without any cause, feeling weak, anger and acting impulsively. History of recent excess Ethanol intake was found in 6 chronic ethanol abusers (5.4\%). Psychiatric co-morbidities were 4 (3.63\%) i.e. major psychosis (schizophrenia, bipolar affective disorder and major depression) on antipsychotics, who attempted deliberate self-harm in the past more than once.

These patients revealed that their mind was disturbed for the past 3weeks to 3 months due to various reasons. Each person spent 1- 24 hours to plan and complete the effort. Majority (88 i.e.80\%) were highly impulsive at the time of attempt, a third of which had associated anxiety and insecure feelings (26cases). No particular personality traits were found (ex. hostility). No Parasuicide cases were seen (self-injuring without desire to die); all were attempted suicide, definite, determined serious efforts to die). None of the elders in the study had revealed their suicidal intention to any family members or friends before the attempt, none of them left a death note. None of these cases had family history of completed suicide. Suicide warning signs like piling drugs, suicidal expression, were not monitored by any family members. Clinically, depressed mood and weeping was found. Cognition was normal in most of the cases except in 2, who were 75-80years aged and had mild dementia. About 25 cases had predominant changing physical pains, minor chronic knee arthritis and spondylosis, pains being disproportionate to illness (involution depression). The interval between the last hospital visit and suicide completion varied from 6 months to 2 years for physical illness, but not for any psychiatric symptoms, in only 10 cases. ${ }^{6}$ Recent demise of spouse was reported in 3 (bereavement). 44 cases lived in isolation voluntarily along with spouse, after getting the children married.

Elder abuse was found in 5 cases between 78- 85 years i.e. neglect and physical harm (4.5\%). All these were physically weak and undernourished. It is interesting to note that Subsyndromal depression i.e. mild depression, symptoms not meeting criteria for Major depression was seen in 80 cases $(72 \%){ }^{8}$

There were 14 suicide attempts which resulted in death i.e. mortality in this study was $11.2 \%$.

Death was probably precipitated by underlying medical illnesses. The hospital stay was from 2-12 days. Postmortem of all 14 was attended and no additional information was available. The ratio of suicide attempt to completion was (124: 14), 7.8: 1. No single survivor came for follow up after the suicidal attempt over 25 months of study period.

DISCUSSION: Out of 980 cases admitted for suicide attempt, 124 were in elderly age group i.e. prevalence of $7.9 \%$, men twice outnumbered women. The rate of suicide for women typically declines after age 60 (after peaking in middle adulthood, ages 45-49). ${ }^{9}$ All cases belonged to Hindu religion 10. 
In Muslim countries (ex-Kuwait), committing suicide is strictly forbidden, total suicide rate is close to 'zero' $(0.1 / 100,000) .11$

The significant sociofamilial factors were poverty, retirement, death of spouse (bereavement), adjustment problems with grownup children / their spouse and isolation. Nuclear family set up does not respect tradition of caring elder parents, even large household in many families gave no psychological support for the victims due to difficult livelihood, in contrast to the earlier observation and paradoxically, there was no family integration though was living in one family ${ }^{12,13}$. Role of Alcohol is significant, chronic alcohol intake is associated with depression. 2,14 Depression has been reported as the most common mood disorders are generally underdiagnosed in older adults and subsyndromal depression is especially common among older persons and is associated with an increased risk of developing major depression. ${ }^{15,16}$ In Asia the role of mental illness in suicide is not as important as that in Western countries, acute life stress (e.g., family conflicts, job, financial) plays more important role and, there is higher average suicide rate, and higher elderly-to-generalpopulation suicide ratios. ${ }^{17}$ Neurobiological factors in elderly are serotonergic CNS dysfunction which is associated with impulsivity and aggression.

CONCLUSION: Suicide is preventable. Suicide is caused by many psychosocial risk factors (loss of social roles, the death of closer ones, declining health, isolation, financial constraints and decreased cognition); these produce feelings of hopelessness and depression. In India poverty is also a major risk factor which predisposes to depression. ${ }^{18}$ Anxiety in association with depression was found in $1 / 3^{\text {rd }}$ of cases here. ${ }^{19}$ An estimated $10 \%$ of persons above 65 years of age are abused. ${ }^{2}$ Illnesses in them are misdiagnosed, overlooked or dismissed as the normal process of aging. Depression is not a normal part of aging. Omitted may be many "silent suicides", ex - completions from medical noncompliance and overdoses, self-starvation or dehydration and accidents.

The National Strategy for Suicide Prevention creates a framework for suicide prevention for the nation. It is designed to encourage and empower groups and individuals to work together. ${ }^{20}$ Group intervention for caretakers of geriatric patients on outpatient basis should be available. ${ }^{21}$ The World Health Organization's (WHO's) suicide prevention multisite intervention study on suicidal behaviors (SUPRE-MISS), has revealed that it is possible to reduce suicide mortality through brief, low-cost intervention in developing countries. ${ }^{22}$ The importance of spiritual health is by spiritual awareness at every stage, in everyone (patient, care taker, society)in order to overcome stresses and improve self-esteem and to remember always that, killing 'self' is a $\sin .{ }^{23}$ Mild depression (subsyndromal depressive disorder) has to be always remembered.2, 4, 8, 15, 16, 24 All 3 Durkheimian types of suicides occur in the elderly - a sense of isolation leads to "egoistic suicide", social deregulation and normlessness predispose to "anomic suicide", and some seniors eliminate themselves to 'unburden' their family (the "altruistic type"). David Émile Durkheim (French sociologist) proposed that suicide is always an outcome of social / societal situations, and JeanÉtienne Dominique Esquirol (French psychiatrist) wrote that "All those who committed suicide are insane".2 


\section{REFERENCES:}

1. World health organisation. Prevention of suicide. Public Health Paper No.35, Geneva: WHO, 1968.

2. Kaplan \& Sadock's Synopsis of Psychiatry: Behavioral Sciences/Clinical Psychiatry, 10th Edition 2007, Lippincott Williams \& Wilkins, pg 568-570, 898, 1348-1358.

3. AGEING IN INDIA prepared for WHO by Dr Indira Jai Prakash, Professor of Psychology, Bangalore University, Bangalore, India, WHO, Geneva 1999.

4. Irudaya Rajan. S. Population ageing and health in India first published in July 2006 by The Centre for Enquiry into Health and Allied Themes (CEHAT), Mumbai.

5. Park's Text Book Preventive and Social Medicine: 21st Edition, Banarasidas Bhanot Publishers, Page no. 513.

6. Conwell Y, Brent D. Suicide and aging: patterns of psychiatric diagnosis. International Psychogeriatrics 1995; 7(2): 149-64.

7. Reynolds III CF (et al). Nortriptyline and interpersonal psychotherapy as maintenance therapies for recurrent major depression: a randomized controlled trial in patients older than 59 years. Journal of the American Medical Association 1999; 281(1): 39-45.

8. Horwath E, Johnson J, Klerman GL, Weissman MM. Depressive symptoms as relative and attributable risk factors for first-onset major depression. Archives of General Psychiatry1992; 49(10): 817-23.

9. National Center for Injury Prevention and Control (NCIPC) operated by the Centers for Disease Control and Prevention (CDC). [Updated 2008].

10. Arun M. Parasuicide - an approach to the profile of victims. JIAFM 2004; 26(2). ISSN 0971-0973.

11. José Manuel Bertolote, Alexandra Fleischmann, A global perspective in the epidemiology of suicide Suicidologi 2002, årg. 7, nr.2.

12. Ajit Shah. The relationship between elderly suicides rates, household size and family structure: A cross-national study. Indian Journal of Psychiatry in Clinical Practice 2009; 13(4):259-264.

13. Venkoba Rao A. Suicide in the elderly: A report from India. Crisis: The Journal of Crisis Intervention and Suicide Prevention1991; 12(2):33-39.

14. McIntosh JL. Alcoholism is common among Patients who commit suicide, McIntosh JL for the American Association of Suicidology. USA Suicide: 1999.

15. Horwath E, Johnson J, Klerman GL, Weissman MM. Depressive symptoms as relative and attributable risk factors for first-onset major depression. Archives of General Psychiatry, 1992; 49(10): 817-23.

16. Alexopoulos GS. Mood disorders. In: Sadock BJ, Sadock VA, eds. Comprehensive Textbook of Psychiatry, 7th Ed, Vol. 2. Baltimore: Williams and Wilkins, 2000.

17. Ying-Yeh Chen, Kevin Chien-Chang Wu, Saman Yousuf and Paul S. F. Yip. Suicide in Asia: Opportunities and Challenges, Epidemiol Rev 2012; 34 (1): 129-144.

18. Kuruvilla A, Jacob K.S. Poverty, social stress \& mental health. Indian J Med Res2007; 126: 273278.

19. Kua, E. H., Ko, S. M., Fones, C. S. L., et al. Comorbidity of depression in the elderly. International Journal of Geriatric Psychiatry 1996; 11: 699 -704.

20. Department of Health \& Human Services. National strategy for suicide prevention. [Updated 2008]. 
21. J. Henry et al Group intervention for carers of geriatric patients: experiences from a clinic in India. International Psychiatry 2010; 7(2).

22. Vijaykumar L. Suicide and its prevention: The urgent need in India. Indian J Psychiatry2007; 49:81-4.

23. K. E. Sadanandan Unni. Human Self Destructive Behaviour. In: Textbook of postgraduate Psychiatry, 2nd edition, vol 2, J Vyas, Niraj.

24. José L. Ayuso- Mateos. From depressive symptoms to depressive disorders: the relevance of thresholds. The British Journal of Psychiatry2010; 196(4): 365-371.

\section{AUTHORS:}

1. P.N. Venkatarathnamma

2. Mohan Reddy

3. A.L. Yashwanth

4. Anil Kumar Mannava

5. Gautham Gundabolu

\section{PARTICULARS OF CONTRIBUTORS:}

1. Professor, Department of Medicine, Sri Devaraj Urs Academy of Higher Education and Research, Tamaka, Kolar, Karnataka, India.

2. Professor, Department of Psychiatry, Sri Devaraj Urs Academy of Higher Education and Research, Tamaka, Kolar, Karnataka, India.

3. Post Graduate Student, Department of Medicine, Sri Devaraj Urs Academy of Higher Education and Research, Tamaka, Kolar, Karnataka, India.
4. Post Graduate Student, Department of Medicine, Sri Devaraj Urs Academy of Higher Education and Research, Tamaka, Kolar, Karnataka, India.

5. Post Graduate Student, Department of Medicine, Sri Devaraj Urs Academy of Higher Education and Research, Tamaka, Kolar, Karnataka, India.

\section{NAME ADDRESS EMAIL ID OF THE CORRESPONDING AUTHOR:}

Dr. P.V. Venkatarathnamma, Professor, Department of Medicine, Sri Devaraj Urs Academy of Higher Education and Research,

Tamaka, Kolar, Karnataka, India.

E-mail: drpnvr@rediffmail.com

Date of Submission: 18/01/2014.

Date of Peer Review: 20/01/2014.

Date of Acceptance: 30/01/2014.

Date of Publishing: 13/02/2014. 